\title{
Probabilistic approach to the investigation of the causes of emergencies at the gas pipeline facilities
}

\author{
Victor Orlov ${ }^{*}$ and Elena Detina \\ Moscow State University of Civil Engineering, Yaroslavskoe shosse, 26, Moscow, 129337, Russia
}

\begin{abstract}
When developing any technical process, there is a problem of its safety. The solution of these problems is an integral part of such a process. In this work we study the modeling of the dynamics of causeeffect relationships of the origin of accidents at the gas pipeline facility. Publications have been analysed on the solution of the security problem at the gas pipeline facilities, approaches to solve this problem, efficiency of practical implementation on the production site. Based on the analysis, positive aspects of the existing developments were taken into account, and also general significant shortcomings were revealed. This study proposes improvements of security solutions based on the probabilistic approach, allowing the use of quantitative and qualitative criteria in the algorithm of the prevention of security measures and obtaining the possibility of the prevention of emergency situations on gas pipeline objects. The obtained results can be adapted to other branches of production.
\end{abstract}

\section{Introduction}

Currently, in the leading organizations of oil and gas production and processing $[1,2,3]$, the European API implements the life-cycle management system of the facility in accordance with the international standard API RP 581 (American Petroleum Institute). [4] The Risk Management is carried out in all phases of the life cycle. The Risk Based Inspection (RBI) methodology is widely used at the international level, especially in the oil and gas industry. [5, 6] In the literature, several RBI projects are reported, demonstrating the strengths of the approach to risk management and optimization of inspection schedules. The API RP 581 is a well proven methodology for conducting risk-based inspections (RBIs) in the processing industry. The third edition of the standard was published only in April 2016.

The article proposes an expanded solution to security problems based on the probabilistic approach, which makes it possible to use quantitative criteria in preventing security measures and obtaining the possibility of prevention of emergency situations.

\footnotetext{
Corresponding author: OrlovVN@mgsu.ru
} 
Presented, improved, the system ensures the effective operation of facilities and resources in conditions of limited financial resources, where the main goal is to achieve a balance between costs, risks and required asset performance. [7]

The procedure for improving security measures entail the possibility of prevention of emergencies at a hazardous production facility (hereinafter referred to as "GRO"). The safety of the GRO is related to the risk of an emergency. In order to prevent, in the future, to forecast emergency situations at the site, it is necessary to learn how to manage risks.

However, the importance of risk from the point of view of management is not determined by one parameter, which is related to its probabilistic nature. Obviously, the risk, which in the case of implementation carries great losses, can be considered dangerous and requiring management. But if the probability of this risk is extremely small, then it can be neglected. Accordingly, and vice versa: risk with a small potential loss, but realized very often, will lead eventually to a significant total damage. Accordingly, it is necessary to characterize each specific risk with the help of two of its main parameters: the probability of occurrence and the impact of possible damage.

Note that although the effects of risks are not only financial, but also causing loss of life and health, the European systems accept financial, material as the main ones. This is due to the fact that in most cases non-financial losses can be expressed, although with a certain degree of conventionality, in value terms, and also because in the economic activities these kinds of losses are of the greatest importance.

\section{Methodology}

For the first time in Russia, the concept of risk-oriented management of oil, gas and related production and processing facilities appeared at the end of the XIX century. Various methods are used to assess security risks, including statistical analysis, analysis of species and consequences of failures, analysis of the tree of events, and others. As a data source, for statistical analysis of accidents on the gas pipeline, information was used. [8]

As a criterion for the acceptability of risk, the ALARP principle is applied (As Low As Reasonably Practicable - the risk is so low as it is reasonable). [9] The acceptable level of risk in accordance with the principle of ALARP is a level of risk for which the costs of achieving it are economically justified. The results of the risk assessment are presented in the form of a risk matrix, which is constructed in accordance with the methodology. [4] Table 1 presents the types of possible accidents at the pipeline with the probability of occurrence and damage for the period 2014-2017.

Table 1. The probability of occurrence of accidents of various types on the gas pipeline with subsequent damage from the accident for the period 2014-2017.

\begin{tabular}{|c|c|c|c|c|}
\hline Type of accident & $\begin{array}{c}\text { Probability } \\
(2014)\end{array}$ & $\begin{array}{c}\text { Damage, rubles } \\
(2014)\end{array}$ & $\begin{array}{c}\text { Probability } \\
(2015)\end{array}$ & $\begin{array}{c}\text { Damage, rubles } \\
(2015)\end{array}$ \\
\hline $\begin{array}{c}\text { (1) release of a } \\
\text { hazardous substance }\end{array}$ & 0 & 0 & 0,11 & 8834233321,78 \\
\hline (2) fire & 0,37 & 2320799970,81 & 0,26 & 20613211084,16 \\
\hline $\begin{array}{c}\text { (3) destruction / } \\
\text { damage to structures }\end{array}$ & 0,42 & 2652342823,79 & 0,19 & 14723722202,97 \\
\hline $\begin{array}{c}\text { (4) destruction / } \\
\text { damage of technical } \\
\text { devices }\end{array}$ & 0,05 & 331542852,97 & 0,33 & 26502699965,35 \\
\hline
\end{tabular}




\begin{tabular}{|c|c|c|c|c|}
\hline (5) explosion & 0,16 & 994628558,92 & 0,11 & 8834233321,78 \\
\hline (6) spills & 0 & 0 & 0 & 0 \\
\hline Type of accident & $\begin{array}{c}\text { Probabilit } \\
\text { (2016) }\end{array}$ & $\begin{array}{c}\text { Damage, rubles } \\
(2016)\end{array}$ & $\begin{array}{c}\text { Probabilit } \\
\text { (2017) }\end{array}$ & $\begin{array}{c}\text { Damage, rubles } \\
\text { (2017) }\end{array}$ \\
\hline $\begin{array}{c}\text { (1) release of a } \\
\text { hazardous substance }\end{array}$ & 0,17 & 2599689444,67 & 0,1 & 50032740,32 \\
\hline $\begin{array}{c}\text { (2) fire } \\
\begin{array}{c}\text { (3) destruction / } \\
\text { damage to structures }\end{array}\end{array}$ & 0,08 & 1299844722,33 & 0,37 & 187622776,21 \\
\hline $\begin{array}{c}\text { (4) destruction / } \\
\text { damage of technical } \\
\text { devices }\end{array}$ & 0,54 & 8448990695,17 & 0,32 & 162606406,05 \\
\hline $\begin{array}{c}\text { (5) explosion } \\
\text { (6) spills }\end{array}$ & 0,04 & 649922361,17 & 0,1 & 50032740,32 \\
\hline
\end{tabular}

In Fig. 1 and Fig. 2 static information on accidents of various types in the period 20142017 is presented, formed on the basis of the reporting documentation. [8, 7]

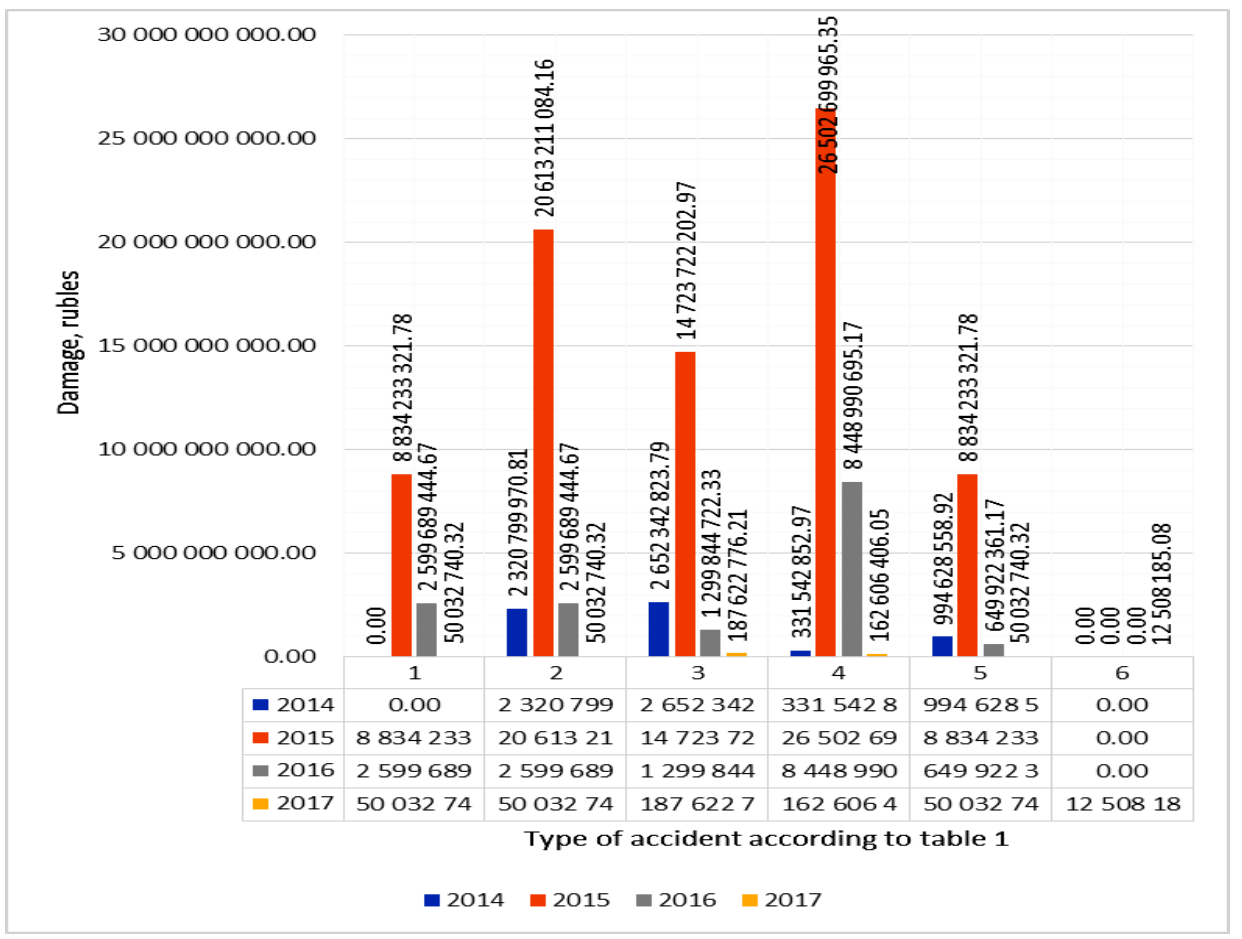

Fig. 1. Statistics of emergency situations on gas pipelines from 2012 to 2017. 


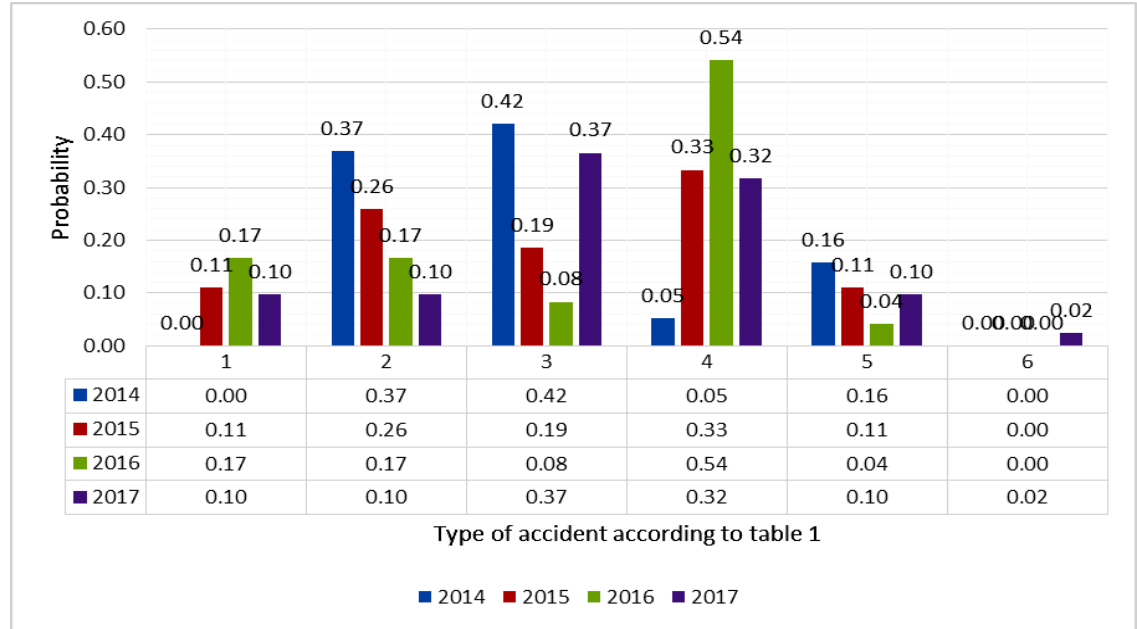

Fig. 2. Statistical probability of accidents of various types at gas production and transportation facilities in the period 2014 - 2017.

In accordance with the statistical data on accidents on the gas pipeline for the period 2014-2017, Table 1, Fig. 1, Fig. 2, we form the risk matrix of Fig. 3. [11] Risk matrix - a picture of risks in the form of a table, where the columns show the magnitude of the damage from the implementation of risks, and by lines - the gradation of the probabilities (or frequencies) of their implementation. Each cell of the matrix contains information about the probability of this event and the amount of possible financial damage. The results of the analysis and risk assessment are ranked by importance in order to establish the optimal balance between costs, risks and performance indicators. Risk matrix which a certain number of rows and columns, and ultimately consists of the areas of four categories: 1) a low risk area (the probability value is from 0 to 0.1 , the damage is from 0 rubles to 1000000000 rubles); 2) the area of an average risk (probability from 0.1 to 0.4 , the amount of damage from 1000000000 rubles to 6000000000 rubles); 3) high risk area (probability value from 0.4 to 0.7 , the amount of damage from 6000000000 rubles to 2 billion rubles); 4) area of extremely high risk (the probability value is from 0.7 to 1 , the amount of damage from 20000000000 rubles and above). It should be noted that the presented risk matrix, depending on the time period, can undergo changes.

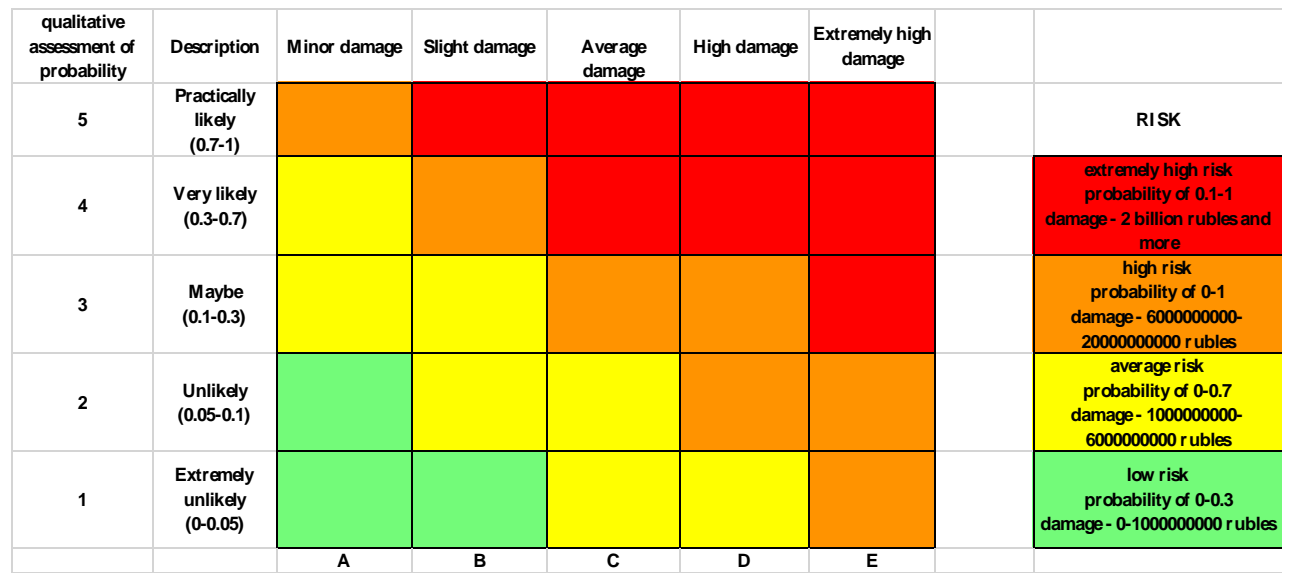

Fig. 3. Risk matrix for gas pipeline facilities for 2014-2017. 
Analyzing the reporting documentation for accidents at gas production and transportation facilities $[8,7]$, based on the probabilistic approach, we construct the tree of events of the emergence of an emergency situation on the gas pipeline, Fig.4.

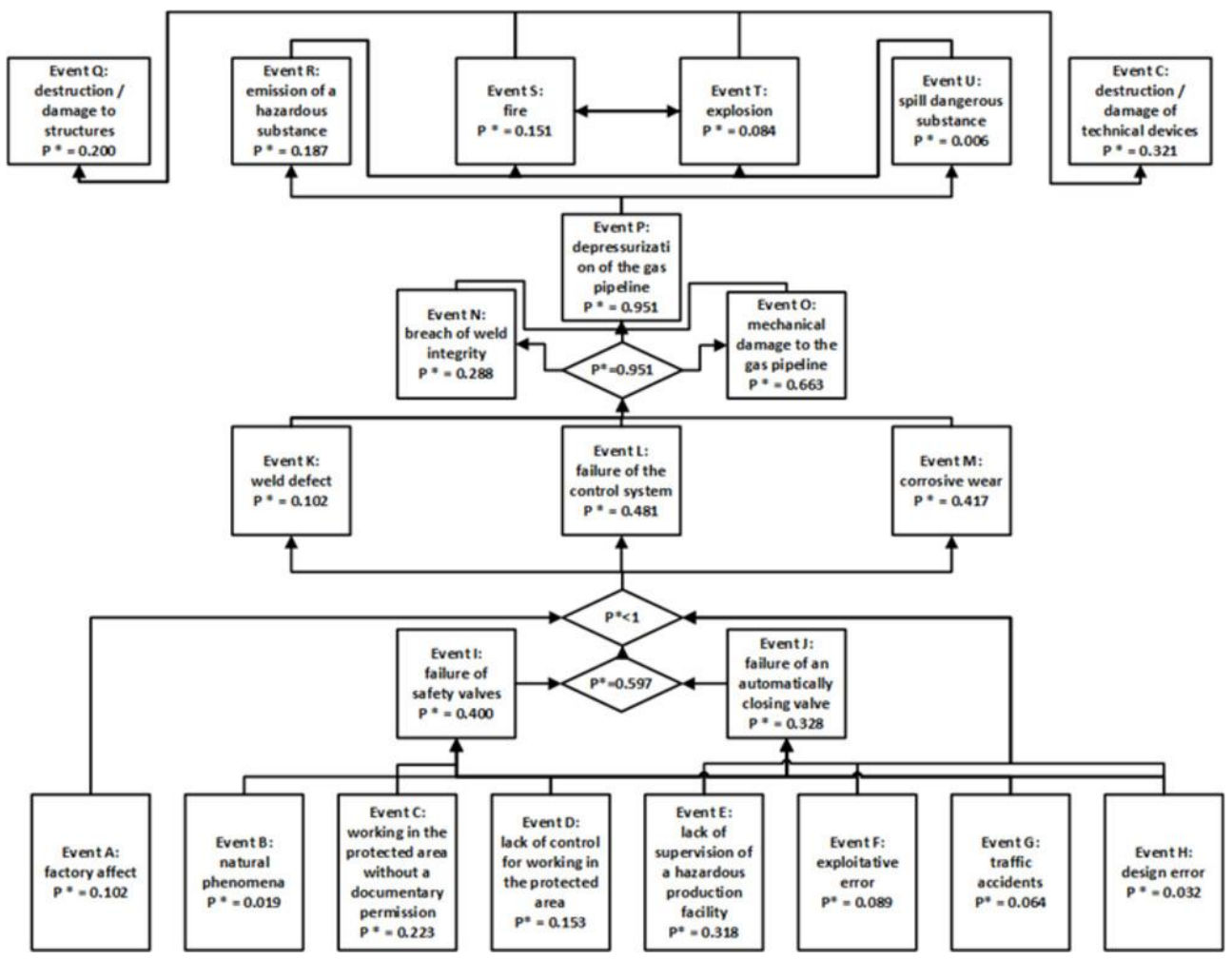

Fig. 4. The tree of adverse events at gas production and distribution facilities.

It is necessary to develop an algorithm for making managerial decisions. [12-14] The following algorithm is proposed:

1. On the basis of the mathematical model developed by the authors of the development of an emergency situation, we obtain a forecast for the planned period of time.

2. We calculate the probability of the projected adverse events.

3. Determine the hazardous areas of the risk matrix.

4. We analyze the tree of events for decision-making on risk management.

5. We form a list of preventive measures to improve security at the site.

And a result, making a management decision to be executed by the relevant structures.

\section{Conclusions}

In the paper the dynamics of the cause-effect relations of the emergence of accidents at the gas pipeline facilities in the form of a tree of events is simulated. The solution of security problems on the basis of the probabilistic approach, which allows using qualitative criteria of the risk matrix in the development of the algorithm for the prevention of security measures, has been improved. For the first time on the basis of predictions of mathematical models, the proposed technology to timely prevent emergencies at gas pipeline facilities. 
The proposed technology of the probabilistic approach to solving the issue of safety of the production process can be successfully implemented in other hazardous industrial enterprises that have significant financial losses associated with emergency situations.

Correlation of the magnitude of risks with the amount of costs for measures to improve safety will allow, under resource constraints, to make management decisions that meet economic criteria.

\section{References}

1. S. Azhar, ASCE Journal of Leadership and Management in Engineering, 11, 241 (2011)

2. D.A. Jordani, Journal of Building Information Modeling, Spring, 13 (2010)

3. S. Roeser, R. Hillerbrand, M. Peterson Epistemology, Decision Theory, Ethics, and Social Implications of Risk (Handbook of Risk Theory, Springer New-York, 2012)

4. API RP 581, Risk-Based Inspection Technology (American Petroleum Institute, 2016)

5. E. P. Zavadskaya, O.A. Kovalchuk, Bulletin of Moscow State University of Civil Engineering, 12, 390 (2017)

6. Terje Aven, European Journal of Operational Research, 253, 1 (2016)

7. Z. Mohaghegh, R. Kazemi, A. Mosleh, Safety Science J., 47, 1139 (2009)

8. Information Bulletin of the Federal Service for Environmental, Technological and Nuclear Supervision, 1, 19 (2018)

9. ALARP Guidance, Note Commonwealth Offshore Petroleum and Greenhouse Gas Storage (Safety) Regulations 2009 (NOPSEMA, 2015)

10. ROSTEKHNADZOR, Annual reports on the activities of the Federal Service for Environmental, Technological and Nuclear Supervision (Moscow, 2014-2017)

11. X. Ruan, Z. Yin, A. Chen, J. Tongji Univ 41, 381(2013)

12. S. Khlynov, Statistics and economy J., 3, 97 (2014)

13. H. Edward, G. Bowmanand, T. Moskowitz, Organization Science J., 12, 772 (2001)

14. G.A. Melhem, A.S. Kalelkar, H. Ozog, S. Saraf, Managing LNG Risks: Separating the Facts from the Myths, (ioMosaic Corporation white paper, 2006) 